\title{
Un mapa para llegar a la vida: estudio de caso de un niño con leucemia mediante arteterapia
}

\author{
Mónica REYNA MARTÍNEZ ${ }^{1}$ \\ monica.reymar@gmail.com \\ Rocío Angélica GONZÁLEZ ROMO² \\ angelicaglzr@psicologia.uaslp.mx \\ Jose Alfredo LÓPEZ HUERTA ${ }^{3}$ \\ jalfredolopezh@gmail.com
}

Enviado: 30/03/2011

Aceptado: 05/08/2011

\section{RESUMEN}

Se realizó un estudio cualitativo mediante un programa de Arteterapia con enfoque cognitivo en un niño convaleciente a causa de la leucemia, con el objetivo de desarrollar estrategias de afrontamiento favorables y minimizar el impacto emocional frente a la enfermedad. Para tales efectos se planearon las etapas de: sensibilización-psicoeducación, recorrido simbólico y cierre; en las que se incluyeron temáticas como el cáncer, tratamiento médico, hospitalización, efectos colaterales, autoconcepto y muerte. Los resultados muestran el desarrollo de un proceso creativo favorecedor para el aprendizaje de formas de afrontamiento, que permiten un mejor manejo y resolución de conflictos emocionales.

Palabras clave: Arteterapia, enfoque cognitivo, leucemia, afrontamiento, emociones.

\section{Referencia normalizada}

REYNA M., GONZÁLEZ R. A., LÓPEZ J. A. (2011). "Un mapa para llegar a la vida: estudio de caso de un niño con leucemia mediante arteterapia". En Arteterapia: Papeles de arteterapia y educación artística para la inclusión social Vol.: 6. Páginas 151-167. Madrid. Servicios de publicaciones UCM.

\section{SUMARIO}

Introducción. Leucemia y etapas generales del cáncer. Afrontamiento al cáncer infantil. Arteterapia con orientación cognitiva. Método. Procedimiento. Resultados. Conclusiones. Referencias bibliográficas.

\footnotetext{
${ }^{1}$ Licenciada en Psicología, Universidad Autónoma de Coahuila. Maestra en Psicología, Universidad Autónoma de San Luis Potosí, México. Arteterapeuta, Capacitación de grupos mediante Arteterapia cognitiva. Equipo de investigación Arteterapia Psicología UASLP

${ }^{2}$ Docente Investigador Facultad de Psicología UASLP. Licenciada en Psicología y Especialista en Orientación Educativa UASLP, Master en Creatividad Aplicada, USC., Maestría en Investigación en Psicología Aplicada a la Educación, UV. Equipo de Investigación Arteterapia Psicología UASLP.Estudio de caso apoyado con recursos del proyecto FAI C08-FAI-10-32.68 "Modelo de diagnóstico e intervención sobre estilos de afrontamiento dirigido a personal de apoyo, pacientes oncológicos y cuidadores primarios"

${ }^{3}$ Docente Investigador en la Facultad de Psicología de la UASLP. Licenciado en Psicología UASLP, Maestría en Educación. Universidad Autónoma de Aguascalientes. Doctorado en Filosofía con Especialidad en Psicología. (Programa en el PNPC) Universidad Autónoma de Nuevo León
} 


\title{
A map to get to life case study of a child with leukemia through art therapy
}

\begin{abstract}
A qualitative study was performed in which an Art therapy program with cognitive approach, was used on a child in the convalescent stage of Leukemia. The foregoing was aimed to minimize the emotional impact against cancer. The contents of intervention revolved around six themes: 1) cancer, 2) medical treatment, 3) hospitalization, 4) human body (following side effects), 5) self-concept and 6) death; the themes were allocated in three stages: a) awareness-psychoeducation b) symbolic path and c) closing. The outcomes of intervention show that creative activity arising during the art therapy process developed a creative process that allowed the resolution of emotional conflicts resulting from the disease. This could be done because of ventilation of emotions and experiences through the creative ways used, also because of cognitive learning of coping ways favorable to child cancer.
\end{abstract}

Keywords: Art therapy, aproach cognitive, leukemia, coping, emotions.

\section{CONTENTS}

Introduction. General stages of leukemia and cáncer. Coping with childhood cancer. Cognitiveoriented art therapy. Method. Procedure. Results. Conclusions

\section{INTRODUCCIÓN}

En México, se estima que el tipo de cáncer infantil de mayor ocurrencia en este país es la leucemia, principalmente la linfoblástica aguda (L.L.A) con un $75 \%$ de casos (Secretaría de Salud, 2007). Ante esta incidencia de cáncer y los problemas psicosociales suscitados durante el proceso de enfermedad, disciplinas como la Psicología de la Salud y la Psicooncología hacen énfasis en la importancia de ofrecer además de una atención médica oportuna, una atención psicológica eficaz a los niños enfermos con cáncer. Lo anterior resulta indispensable, debido a que la conjunción de acontecimientos es tan fuerte que provoca un desajuste emocional en el niño enfermo; lo cual se explica en gran medida por las valoraciones negativas de la enfermedad, las estrategias de afrontamiento poco favorables que dificultan el manejo apropiado de las circunstancias adversas, las emociones negativas que van emergiendo, entre otros.

Dentro de las alteraciones que pueden experimentar los niños afectados están la depresión, estrés, ansiedad, miedos, angustia, fatiga, dificultades para establecer y mantener relaciones interpersonales, incertidumbre frente al futuro, baja autoestima, culpa, dependencia, sentimientos de inutilidad, aislamiento, indefensión, entre otros (Osorio, 2007). Por tal razón existe un importante interés por abordar y comprender los tipos de afrontamiento o manejo que ponen en práctica, ya que por lo general cuando el cáncer se valora como una amenaza, causante de pérdidas y/o daños, se suelen utilizar estrategias de afrontamiento inadecuadas, como por ejemplo la negación, evitación, represión emocional, etc. Por lo que si el enfermo no logra modificar esas respuestas o no aprende a manejar adecuadamente los problemas (físicos, psicológicos y sociales) que se presentan en el mismo proceso, podría maximizar el impacto del padecimiento, dificultar la adaptación al nuevo estilo de vida e incidir 
en un malestar psicosocial haciendo poco soportable la carga emocional. Atendiendo a los lineamientos y recomendaciones de la Psicología de la Salud y la Psicooncología, es importante llevar a cabo intervenciones psicoterapéuticas eficaces que cumplan con la recuperación de la salud mental en esta población. En este caso a través del Arteterapia bajo un enfoque cognitivo, con la finalidad de conducir al paciente a desarrollar un proceso creativo que permita el aprendizaje de nuevas estructuras de pensamiento y formas de actuar, la resolución de conflictos emocionales a través de formas de afrontamiento tales como la expresión emocional, reevaluación positiva, planificación, resolución de problemas, apoyo social, entre otros.

\section{LEUCEMIA Y ETAPAS GENERALES DEL CÁNCER}

La leucemia aguda es una enfermedad compleja, debido en gran parte a que su etiología es desconocida, por otro lado porque es un padecimiento generalizado que conlleva el riesgo de que diferentes órganos y tejidos estén infiltrados por células leucémicas al momento del diagnóstico. (Osorio, 2007). Lo anterior vuelve a la enfermedad grave ya que se desatan distintas situaciones difíciles que impactan al niño enfermo. Diferentes autores como Gallar (2007) dividen al cáncer en etapas, las principales son: 1) Diagnóstico: para ello se realizan las pruebas pertinentes y se confirma el tipo de cáncer; 2) Fase de estado de enfermedad, donde ocurre la hospitalización y tratamiento médico; 3) Convalecencia: el cuadro clínico va desapareciendo hasta llegar lentamente a la curación.

Emociones en el proceso de enfermedad. Tras el surgimiento de una enfermedad como el cáncer, se experimentan una variedad de sentimientos y emociones, como la tristeza, miedo, enojo, entre otros, que en su mayoría son comunes dado el impacto que produce un padecimiento amenazante para la vida. Ante la emergencia de esta mezcla de emociones, existen ocasiones en las que los pacientes niegan, evitan o suprimen la expresión de las mismas (Rodríguez, Esteve \& López, 2002). Las emociones positivas parecen jugar el papel de mantener o recuperar el equilibrio en un organismo, preservando la salud, mientras que las emociones negativas afectan desfavorablemente, llegando incluso a desencadenar o coadyuvar en el desarrollo de enfermedades, además pueden ser responsables de las fases de crisis o agravamiento, tal como las recaídas o recurrencias en diversos trastornos. Por tal razón se crea la necesidad de la expresión o ventilación de emociones durante el proceso del cáncer, para beneficiar psicológicamente por su efecto catártico, siendo suficiente en algunos casos para el ajuste emocional (Romero, 2003).

\section{AFRONTAMIENTO DEL CÁNCER INFANTIL}

El niño con cáncer y la familia, suelen presentar una amplia variedad de respuestas emocionales a lo largo del proceso de la enfermedad, que van desde la aceptación hasta su más completo rechazo o negación. Sin embargo es común que experimen- 
ten una serie de respuestas para enfrentar el diagnóstico de cáncer, su control y su pronóstico (Romero, 2003). Este tipo de respuestas es el resultado de cómo las personas involucradas en el cáncer evalúan la enfermedad, valorándola ya sea como una amenaza, daño, pérdida o desafío (Pérez, 1999). Lazarus y Folkman señalan que el afrontamiento o manejo "se relaciona con el modo en que las personas resuelven o se sobreponen a las condiciones vitales que son estresantes" (Lazarus, 1999, p.114). Los estilos de afrontamiento que se pueden utilizar son 1) centrado en la emoción, el cual dirigido a la regulación de las emociones para obtener un ajuste psicológico, ya que no se modifica la situación por considerar que no es posible hacerlo en ese momento; 2) centrado en el problema, encaminado a enfrentar y modificar la problemática estresante en cuestión.

\section{ARTETERAPIA CON ORIENTACIÓN COGNITIVA}

Loth y Malchiodi (2002) mencionan que el enfoque cognitivo en Arteterapia se basa en la representación de conflictos, sentimientos, emociones, etc., a través del dibujo, la pintura, el collage y/o la escultura, es decir, que el paciente tiene la oportunidad de materializar o exteriorizar el problema que lo aqueja a través del arte. El papel del arteterapeuta es cuestionarlo para propiciar la reflexión con la ayuda del producto artístico, además lo guía en el proceso para que analice el problema ya sea de manera verbal o no verbal. Por otra parte, exponen que el paciente se puede valer de la manipulación de los productos artísticos al cambiarlos, modificarlos o agregar elementos, todo esto después de haber meditado y analizado sobre su problema, como una forma de reestructuración con el fin de otorgarle un significado positivo al conflicto. La meta de este enfoque es la de ayudar al paciente a identificar valoraciones, comportamientos, sentimientos, emociones, etc., falsas y negativas, por otros más realistas y adaptativos, a través de estrategias cognitivas y artísticas.

Vigotsky (2006) menciona que el cerebro humano no sólo es capaz de conservar o reproducir nuestras experiencias pasadas, sino que también es un órgano creador y combinador, capaz de reelaborar y crear con elementos de experiencias pasadas nuevas normas y planteamientos. A su vez menciona que es precisamente que a través de la actividad creadora el hombre "hace de él un ser proyectado hacia el futuro, un ser que contribuye a crear y que modifica su presente" (Vigotsky, 2006, p. 13). La actividad creadora, implica un proceso cognitivo, que involucra el uso de la imaginación, lo que permite a los individuos organizar o reorganizar imágenes, combinar o recombinar símbolos, conduciéndolo a la construcción de nuevos significados, para establecer y conseguir representaciones coherentes, reestructurar eventos pasados, encontrar conexiones significativas, obtener inferencias y resolver problemas. La creación de nuevas posibilidades, sucede porque las obras de arte, a menudo hacen exigencias cognitivas del pensamiento, despiertan la búsqueda intelectual, facilitan el cambio a través de un proceso creativo, se desarrollan nuevas capacidades, generan nuevos discursos sobre la interioridad, invitan a pensar sobre problemas y preocupaciones, favoreciendo la construcción de una realidad diferente (Romero, 2006). La obra convocada, pone de manifiesto lo subjetivo del individuo, 
agregándole un significado de acuerdo a su historia de vida y carga emocional, ya que "el objetivo del arte es expresar la experiencia" (Parsons, 2002, p.46). La importancia de la obra y su impacto, van a depender de los sentimientos que se generan cuando el paciente se enfrenta a ella.

\section{MÉTODO}

Diseño de la investigación. El presente estudio se efectuó desde una metodología cualitativa, la cual tiene el objetivo de comprender un fenómeno centrándose en la indagación de los hechos, es decir, que se pretende la comprensión de las complejas interrelaciones que se dan en la realidad, para generar la construcción del conocimiento, por lo que el investigador va interpretando los sucesos y acontecimientos desde el inicio hasta el final de la investigación. El método que se eligió fue el de estudio instrumental de caso, ya que se reporta una situación única de un paciente, de forma anecdótica y cualitativa. Los paradigmas interpretativos que se tomaron como base para desarrollar la investigación son el constructivismo y la fenomenología, debido a que se buscó reconstruir acontecimientos que surgieron a lo largo de la enfermedad a través de la intervención de Arteterapia con orientación cognitiva. Nos centramos en el conocimiento y la comprensión de experiencias personales, así como en el desarrollo de aprendizajes referentes al manejo de emociones y estrategias favorables de afrontamiento en relación al cáncer infantil. Selección de casos. Se optó por una muestra por conveniencia, la cual permite que los individuos sean seleccionados según la conveniencia del investigador, o porque se encontraban disponibles en un tiempo o lugar conveniente. En este caso, el niño participaba en un taller de Arteterapia en la Asociación Mexicana de Ayuda a Niños con Cáncer I.A.P de la ciudad de San Luis Potosí, México (González, R., Reyna, M., Cano, R 2009). Criterios de inclusión. 1. Contar con una edad comprendida entre los 7 y 10 años, debido al desarrollo cognitivo el cual permite al participante comprender y aprender el proceso del cáncer infantil. 2. Hablar y escribir el idioma español, para facilitar el curso de las sesiones para no entorpecer la verbalización y/o la escritura. 3. Padecer L.L.A., debido a la alta incidencia de casos en la población mexicana infantil. 4. Contar con la aprobación y firma del consentimiento informado por parte de la madre.

\section{PROCEDIMIENTO}

Para diseñar la intervención se consideraron las problemáticas psicosociales que suelen presentarse comúnmente ante el proceso de la enfermedad del cáncer infantil: el diagnóstico, el tratamiento médico, la hospitalización y los efectos colaterales. Además se agregaron dos temáticas que emergieron y que se mantuvieron a lo largo de la intervención: el autoconcepto y la muerte. Para llevarla a cabo se empleó el Arteterapia con enfoque cognitivo para tres fines: 1) reconstruir eventos pasados, para la identificación de emociones positivas/negativas y estilos de afrontamiento ante eventos críticos del cáncer infantil; 2) facilitar la expresión emocional y el 
manejo de emociones negativas; 3) facilitar de la comprensión de formas de actuar desfavorables, para propiciar el aprendizaje de estrategias de afrontamiento adaptativas. Las técnicas cognitivas que se emplearon a lo largo de la intervención fueron: la psicoeducación, el biofeedback, ejercicios de relajación y respiración, la imaginación guiada, imágenes emotivas y la dramatización. Mientras tanto, las actividades artísticas empleadas para la creación de las obras de arte fueron: el collage, la pintura, el dibujo y el modelado.

Las etapas de la intervención y en las cuales fueron distribuidas las temáticas anteriormente mencionadas, se muestran en la siguiente tabla:

\begin{tabular}{|c|c|c|}
\hline Etapas & Objetivos & Actividades \\
\hline 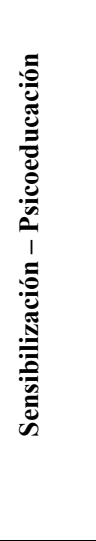 & $\begin{array}{l}\text { - Conocer qué es el Arte terapia y en qué } \\
\text { consiste. } \\
\text { - Conocer nuevas formas para relajarse y su } \\
\text { importancia } \\
\text { - Conocer, denominar e identificar las } \\
\text { emociones de enojo, alegría, miedo, y pre- } \\
\text { ocupación. } \\
\text { - Ejemplificar las emociones para facilitar } \\
\text { su identificación a lo largo de la interven- } \\
\text { ción. } \\
\text { - Conocer e informarse acerca del signifi- } \\
\text { cado del cáncer, la leucemia, tratamiento y } \\
\text { efectos colaterales. }\end{array}$ & $\begin{array}{l}\text { - Encuadre } \\
\text { - Técnicas de Arteterapia para la sensibiliza- } \\
\text { ción a los materiales y ruptura de hielo. } \\
\text { - Técnicas de relajación } \\
\text { - Biofeedback de emociones } \\
\text { - Técnicas cognitivas sobre identificación de } \\
\text { emociones, intensidad y cómo se manifiestan. } \\
\text { - Psicoeducación acerca del cáncer mediante } \\
\text { videos, explicación gráfica y verbal }\end{array}$ \\
\hline 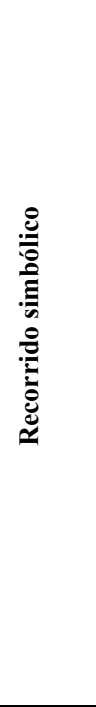 & $\begin{array}{l}\text { - Explorar y expresar los sentimientos y } \\
\text { emociones evocados ante la enfermedad, y } \\
\text { situaciones como el tratamiento médico y la } \\
\text { hospitalización. } \\
\text { - Explorar y expresar los sentimientos y } \\
\text { emociones ante el dolor físico y emocional, } \\
\text { producidos por el tratamiento médico y la } \\
\text { situación de enfermedad. } \\
\text { - Explorar y expresar sentimientos y emo- } \\
\text { ciones ante la muerte. } \\
\text { - Conocer y comprender sus necesidades } \\
\text { emocionales y a sí mismo. } \\
\text { - Conocer y comprender de qué manera ha } \\
\text { reaccionado y actuado frente al cáncer y } \\
\text { situaciones asociadas. } \\
\text { - Conocer nuevas formas de afrontar suce- } \\
\text { sos difíciles y el cáncer. }\end{array}$ & $\begin{array}{l}\text { - Actividades de Arteterapia } \\
\text { - Técnicas cognitivas: Imaginería, relajación, } \\
\text { manejo de emociones y situaciones estresantes. }\end{array}$ \\
\hline
\end{tabular}




\begin{tabular}{|l|l|l|}
\hline & $\begin{array}{l}\text { - Aprender a despedirse de una forma posi- } \\
\text { tiva }\end{array}$ & $\begin{array}{l}\text { • Actividades de Arteterapia } \\
\bullet \text { Psicodrama }\end{array}$ \\
- Llevar a cabo un ritual de despedida del & \\
proceso arteterapéutico y de la arteterapueta. \\
- Estructurarse para seguir con su vida \\
cotidiana
\end{tabular}

\section{RESULTADOS}

A continuación se exponen los resultados y análisis obtenido del caso de estudio que por razones éticas se nombrará con el nombre ficticio de Carlos; en primera instancia se describen las características generales como una forma de introducir al lector al conocimiento de las particularidades del proceso arteteterapéutico del niño.

\section{Datos generales:}

\begin{tabular}{l|l}
\hline Inicio de proceso Arteterapéutico: & 18 de Febrero de 2008 \\
\hline Finalización: & 24 de Marzo de 2009 \\
\hline Número de sesiones: & 36 \\
\hline $\begin{array}{c}\text { Edad al inicio de la intervención psicote- } \\
\text { rapéutica: }\end{array}$ & 7 años \\
\hline Diagnóstico: & Leucemia Linfoblástica Aguda \\
\hline Edad de diagnóstico: & 3 años \\
\hline Tratamiento: & $\begin{array}{c}\text { Quimioterapia, transfusiones de } \\
\text { sangre y sueros }\end{array}$ \\
\hline Enfermedades colaterales: & Bronquitis, Neuropatía crónica \\
\hline $\begin{array}{c}\text { Fase de la enfermedad al momento de la } \\
\text { intervención: }\end{array}$ & Convalecencia \\
\hline
\end{tabular}

Descripción del proceso arteterapéutico: Un mapa para llegar a la vida. Para Carlos la creación artística fue un vehículo que propició el aprendizaje y el desarrollo de estrategias de afrontamiento favorables. Entre ellas adquirió principalmente la expresión emocional, la reevaluación positiva, el desarrollo personal y la resolución de problemas. Además en su proceso arteterapéutico, tuvo la oportunidad de representar y reflejar una variedad de emociones y conflictos que a lo largo de 5 años mantuvo reprimidos, sin embargo finalmente pudo ventilarlos y resolverlos. Se aprecia que mantenía contenidas emociones tales como el enojo, la tristeza, desesperanza, preocupación y miedos, que al mismo tiempo no podía comprender, expresar ni solucionar. Sin embargo, a través de este proceso creativo, tuvo la posibilidad de enfrentarse con su sufrimiento emocional al poder materializar por medio de sus creaciones experiencias difíciles y su mundo interno, como una forma de confrontarse a sí mismo.

Los resultados se plantean a continuación de acuerdo a dos directrices: a) las emociones experimentadas y las estrategias de afrontamiento que utilizó en el pro- 
ceso de la enfermedad, y b) los cambios originados, es decir, el aprendizaje de nuevas formas de afrontamiento y el manejo de las emociones.

Se advierte que la descripción de los resultados no va de acuerdo al orden de las sesiones del proceso arteterapéutico, y que lo que se muestra a continuación solamente representa lo más trascendental de su proceso arteterapéutico. También se busca exponer los cambios suscitados, los cuales no están sujetos a un proceso lineal sino a un proceso creativo y cíclico.

\section{a) Emociones $y$ estrategias de afrontamiento utilizadas en el proceso de enfermedad.}

A lo largo de la etapa de enfermedad y de convalecencia, Carlos solía utilizar un afrontamiento enfocado en la emoción, siendo las estrategias de evitación cognitiva y la represión emocional las que predominaron. En la etapa de sensibilización y en la mayor parte de la etapa de recorrido simbólico, Carlos evitó todo aquello que pusiera en evidencia la leucemia y/o el sufrimiento emocional producido a lo largo del cáncer. Con su primera obra de arte tuvo dificultad para denominar la enfermedad y de reconocerla como un padecimiento que mantuvo por largo tiempo, de esta forma solo se inclinaba a decir que había sido originada "porque no comía bien", "porque comió mucho hielo". Es decir que al poseer valoraciones negativas y al ser ignorante sobre su origen, creyó que la causa desencadenante fue por un castigo y en consecuencia responsable de severos daños que ponían en riesgo su integridad, identificándola como amenazante para su vida.

Su pasividad y escasa disposición para hablar abiertamente sobre la leucemia, lo llevaron a valerse de un recurso valioso: expresar en tercera persona sus propias experiencias por medio de José el niño de su obra ¿Cómo se siente estar enfermo? (Fig. 1). Dejó claro que "se sentía triste y enojado por tener la leucemia dentro de su cuerpo", así mismo agregó que lo único que quería era "gritarle a los demás lo que le pasó". Esta declaración daba cuenta de la necesidad imperiosa que poseía el niño de ventilar emociones y experiencias de profundo dolor emocional contenidas por efecto de un manejo desfavorable, las cuales habían prevalecido por efecto de un embotellamiento emocional por alrededor de cuatro años.

Tratamiento médico y hospitalización. Se lograron examinar e identificar las emociones y formas de afrontamiento ante la quimioterapia y los procedimientos diagnósticos, principalmente las inyecciones, la administración de suero y revisiones médicas de rutina. Tales emociones iban desde la preocupación, la tristeza, el miedo y el enojo; igualmente, se observó que ante la emergencia de las primeras tres se quedaba paralizado, mostraba actitudes pasivas y de indefensión, incluso se tornaba pesimista ante su fututo. Por otro lado, al sentirse desolado se pudo apreciar que Carlos percibía a su entorno contento, encaminándose a pensar que mientras él tenía miedo de que lo "picaran", "el doctor era muy feliz". En cuanto al enojo, refirió que era provocado "porque tenía que ir al doctor y al seguro" y que se incrementaba cuando la enfermera lo "picaba", descargando su coraje con palabras altisonantes y rabietas. En relación a los materiales médicos, identificó y expresó en Las cosas que hay en el seguro, emociones tales como la tristeza, enojo y miedo. 
Dolor. Cuando se abordó el tema del dolor físico, provocado por el mismo tratamiento médico, plasmó y narró a través de su obra Nuestro Cuerpo, el sufrimiento emocional por haberse sentido lastimado y agredido corporalmente. Prevalecieron en él las emociones de miedo anticipado a la llegada del hospital, y el enojo desplazado hacia la enfermera cada vez que le aplicaba los procedimientos médicos que implicaban agujas. Cabe señalar, que también necesitó hablar en tercera persona a través de Héctor, nombre designado a la silueta, lo que le permitió expresar abiertamente su sentir. Además se dio la oportunidad de manifestar en su obra La sangre (Fig. 2) este dolor físico, el cual recordaba con las siguientes características: "era un dolor grande", "muy rojo", con movimiento "como si estuviera batiendo", "rasposo", sintiéndolo principalmente "en las manos". De esta forma podemos percatarnos de que además de mostrarnos de forma visual este dolor, por el color y textura de su obra artística, también nos dio la oportunidad de conocer su magnitud y el nivel de daño psicológico producido. Lo anterior, si observamos que se apoyó en materiales como la brillantina, color y pintura roja, para enfatizar las características del malestar previamente mencionado. Por otro lado, el énfasis que Carlos hizo respecto a esta experiencia lo condujo a asemejar este mismo producto, con una huella dactilar y declarar a la arteterapeuta "las huellas son difíciles de borrar".

Sin embargo no solo a través de esta obra de arte expuso lo difícil que era para él olvidar o comprender esta etapa de su vida, sino que mantuvo la misma temática en gran parte del proceso arteterapéutico. Por ejemplo con su creación ¿Cómo se siente estar enfermo? (Fig. 1) exteriorizó el significado de haber padecido la leucemia, esto al dejar al descubierto desde su propia voz que se sentía "feo, porque unos niños se van [del hospital] y tú ahí te quedas (...) se siente aburrido" y "se siente triste o sino casi enojado, porque no me gusta lo que me hacen". Por otra parte, mediante su producto La cárcel daba muestras de su irritación por el hospital, ya que lo percibía como un lugar desagradable, en el cual sentía como si le "robaran la vida, la sangre y el corazón" al igual que encierro y hastío.

Autoconcepto. La percepción que Carlos tenía de sí mismo estaba devaluada, y eso no le permitía manejarse y enfrentar al mundo de manera positiva. En un inicio se representó con una imagen cruda, tal como lo expone en su obra ¿Cómo se siente estar enfermo? (Fig. 1), en donde lo vemos como un niño constituido pobremente, frágil y vulnerable, ya que la situación de enfermedad le hizo formarse una baja autoestima, debido a su inseguridad, miedo, estado de ánimo abatido y por verse diferente a otros niños. Por ello al construir un cuerpo humano a base de plastilina, presentó dificultades para realizarla por la preocupación de no equivocarse debido a que intentaba hacerlo perfecto. Sin embargo, no le fue posible hacerlo por lo que al concluir la actividad manifestó hostilidad y de forma irónica dijo en diversas ocasiones que "estaba muy feo", con un rostro "horrible" y con "piernas chuecas". Al respecto, hay que mencionar que Carlos sufrió una neuropatía como efecto colateral de la quimioterapia, por lo que eran persistentes los dolores en sus piernas, por lo tanto su producto artístico era un reflejo de la autoimagen "defectuosa" formada.

Miedos. Las experiencias planteadas con anterioridad representaron obstáculos que le impedían pensar que podía llevar una vida normal y en consecuencia llegar a 
la curación. Esto lo llevó a crear obras como El carro, en donde se aprecia un coche con la imposibilidad de transitar y que en última instancia significa una cruda prohibición de su paso libre. Estos impedimentos estaban centrados principalmente en la incomprensión de las experiencias acontecidas en el proceso de la enfermedad y en el pobre manejo de sus emociones como sucedía con los miedos ante la muerte, a los fantasmas y hacia una bruja. En relación al temor de perder la vida, fue claro en reconocer que sentía una gran responsabilidad del estado de ánimo de su madre si esto llegara a pasar, ya que pensaba que la dejaría sola, lo cual hacía la situación estresante.

Por otro lado, antes de introducirnos a los miedos hacia los fantasmas y a la bruja; es importante mencionar que a lo largo del cáncer, es común que los niños presenten efectos colaterales físicos que originan una preocupación en los padres que no están informados. Lo anterior produce acciones erróneas y en este caso, la madre orillada por la desesperación de ver que Carlos no probaba alimento por las náuseas, tuvo la ocurrencia de asustarlo por medio de un personaje imaginario: una bruja. Esto provocó que el niño manifestara conductas tales como dificultad para conciliar el sueño, dormir en compañía de su madre, así como también compulsión por probar alimentos y en consecuencia obesidad. El miedo fue plasmado en sus obras Los fantasmas, con las que se dio la oportunidad de relatar de qué manera había sido asustado, y reveló que al imaginarlos se quedaba "mudo" y sin la oportunidad de enfrentarlos porque tenía miedo de quedarse solo.

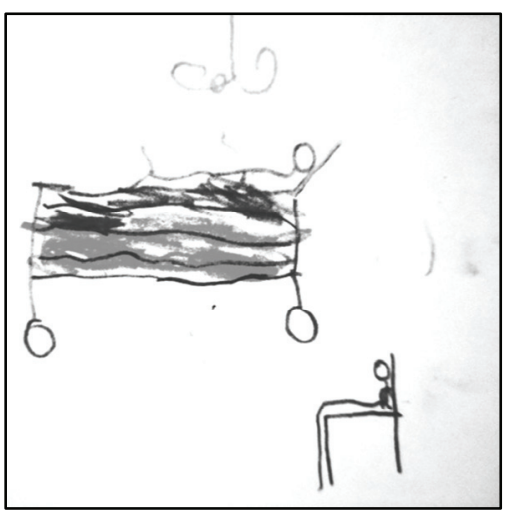

Fig. 1. ¿Cómo se siente estar enfermo?

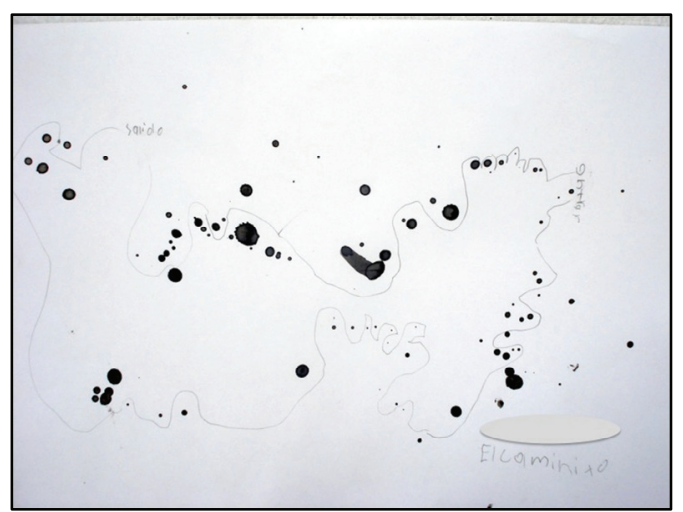

Fig. 2. La sangre

\section{b) Aprendizaje de nuevas formas de afrontamiento}

A continuación se presenta el proceso que tuvo Carlos para afrontar de manera positiva los conflictos psicológicos y se muestra el aprendizaje de nuevas estrategias a partir de 2 periodos: descubrimiento de la necesidad de un mapa para llegar a la vida y la construcción del mapa para la resolución de conflictos.

Descubrimiento de la necesidad de un mapa para llegar a la vida. Resulta sorprendente que en el proceso arteterapéutico el niño reveló sus necesidades a través de la creación de obras artísticas más que con la palabra, ya que en múltiples oca- 
siones se resistía a verbalizar su experiencia. En el mejor de los casos, utilizaba como recurso de expresión a un tercero que hablara por él, ya que le resultaba difícil apropiarse de sus sentimientos y prefería depositarlos en otro(s). No obstante, más allá de los medios que haya utilizado para entablar la comunicación con la arteterapeuta, llegó a un punto en el cual dejó ver su más grande necesidad: "llegar a la vida". Tal vez por sentirse muerto en vida o por la creencia de que la cura sería el indicio del comienzo de ésta. Lo anterior se logró descubrir gracias a dos obras trascendentales y que iluminaron el proceso: Limusina (Fig. 3) y El caminito (Fig. 4).

La primera creación dio cuenta de los obstáculos que avistaba, mismos que no le permitían avanzar porque para ello era preciso hacerles frente, lo que significaba aprender estrategias de afrontamiento diferentes a las centradas en la emoción, como la evitación, represión emocional y negación. Con la segunda obra, descubrió que necesitaba de un camino o un mapa que lo condujera a la vida, por lo que se le invitó a iniciar un proyecto para su construcción. El fin de ello sería la de modificar la creencia de que su pasado había sido sombrío y símbolo de muerte en vida, para lo cual se le alentó (en la etapa del recorrido simbólico) a reconocer la enfermedad como una etapa difícil, gracias a una mayor comprensión dirigida al entendimiento de que su vida no comenzaría en el momento de la curación ya que lo que hacía cada día era vivir.

Construcción del mapa: resolución de conflictos emocionales. En resumen, el proceso acontecido en este trayecto arteterapéutico representó el puente que llevó al niño hacia la resignificación de sí mismo y del mismo cáncer. Con la construcción del mapa, se desataron aspectos significativos que permitieron al niño beneficiarse psicológicamente aunque por momentos se confundiera y tratara de claudicar en la búsqueda de soluciones. En un inicio no sabía de qué manera dibujar los caminos de su mapa, sin embargo más tarde encontró símbolos que representaron sus necesidades emocionales a través de la obra Calles y Símbolos, por lo que se encontró la inclusión de: a) Símbolos de huída y evitación: éstos son el carro, el tobogán y las albercas, ya que le servían para impulsarse fuertemente y emprender la huída antes de que las enfermeras lo "picaran"; en el caso del carro, pudo atribuirle una propiedad de agresividad al mencionar le era de utilidad para atropellar a las personas que le hacían daño. Los controles los necesitaba para cambiar su "vida" porque no le agradaba lo que había vivido. b) Símbolos de defensa y protección: eligió pistolas, un teléfono, robots, un perro, bombas y el águila, revelando que su función era la de defenderlo ante el tratamiento médico por su carácter doloroso.

Este proyecto de construcción fue una valiosa herramienta que dio como resultado una adquisición de recursos emocionales como apoyo para la reevaluación de sucesos críticos y el afrontamiento centrado en el problema. Para ello se insistió en la ventilación de experiencias y en la canalización de emociones negativas a través de la reflexión y creación artística. Con la Canasta de las emociones, pudo percatarse de que las emociones negativas pueden ser canalizadas positivamente; como ejemplo de ello tenemos que Carlos de forma metafórica pudo depositar en tal recipiente el enojo que experimentaba su brazo ante los procedimientos médicos. Se observa que aunque Carlos seguía pensando que el tratamiento había sido doloroso, 
se dio la oportunidad de aceptarlo como una vía para "estar mejor" y poder curarse, tal como lo narró a través de Las cosas que hay en el seguro, donde además reconoció su importancia y beneficio.

En cuanto al hecho de ser hospitalizado en múltiples ocasiones, nos percatamos de que a pesar de seguir percibiendo tal experiencia como fría y desagradable, expresó que tuvo que vivirla para sanar; además observamos que pudo revalorar el papel que jugó el personal médico en su recuperación.

De igual modo, tomó consciencia de que su vida no comenzaría al momento en que se diera la curación de la leucemia, sino que ésta se conformaba de aquellas experiencias acontecidas desde su nacimiento, incluyendo la enfermedad. Lo anterior, se logró gracias a que en todo momento se le brindó la oportunidad de reflexionar, buscar soluciones y resarcir errores, tal como se observó en la creación de la Limusina (Fig. 3), en donde derramó pintura sobre su creación. Aquí la arteterapeuta, al verlo temeroso y sin posibilidades de hacer otra cosa más que descalificar su obra, le planteó la posibilidad de buscar alternativas de solución, sugiriéndole que cualquier elección que hiciera era buena, ya que lo que se pretendía era un aprendizaje de formas para corregir y manejar un conflicto, ya sea dentro o fuera de las sesiones.

Después de todas las enseñanzas se le observó con mayor interés y optimismo al proyectar su vida a futuro, además se apropiaba de un sentimiento de esperanza y lucha activa para llegar a la curación y no recaer. Lo anterior demuestra la madurez emocional y la fortaleza conquistada, que iban de la mano con su cooperación para lograr resolver sus conflictos emocionales. En su camioneta de los deseos titulada Salud de los enfermos expresó la esperanza de tener un futuro "lleno de deseos" y sin amenazas para su integridad. Se hizo más consciente de que para alcanzar los deseos propios, debía trazarse objetivos concretos y poner en marcha un plan, ya que para llegar a una meta u objetivo tenía que actuar.

El hecho de adquirir fortaleza le permitió tomar valor para enfrentar sus miedos. Por ello evocó por segunda ocasión la obra Los fantasmas, para convencerse de que no era posible su existencia ya que eran imaginarios, pero al mismo tiempo dudaba y solamente quería que los miedos salieran de su cabeza. Por esta razón y con el objetivo de que enfrentara sus temores, en este caso hacia una bruja y a los fantasmas, se planteó una tarea que consistió en: 1) la construcción de un súper héroe, para la instalación cognitiva de recursos tales como el autocontrol y la valentía. Construcción de una bruja, que realizó su mamá. 2) Dramatización, para hacer frente a los miedos.

El súper héroe de nombre Varbilla (fig. 5), fue elaborado con mayor concentración y armonía, si se compara con el resto de las obras de arte, las cuales en su mayoría reflejaron la soledad, fragilidad, minusvalía emocional y sufrimiento. Varbilla (fig. 5) tuvo un aspecto fuerte y con músculos para ayudarlo o protegerlo ante situaciones amenazantes; con un escudo multicolor que representaba la gama de poderes, es decir los recursos psicológicos y cognitivos que fueron adquiridos a lo largo del proceso arteterapéutico y que finalmente le ayudarían a enfrentarse a aquella bruja. De esta forma para desafiar sus miedos, fue necesario llevar a cabo la drama- 
tización en dos partes: 1) se dibujó la situación problemática, con una posterior narración del evento para que tanto Carlos como su madre expusieran su versión. 2) se dramatizó la situación conflictiva con la ayuda de juguetes, la bruja y el súper héroe.

En la escena los dos fungieron sus papeles, y en el caso de la madre pudo explicar el principal motivo que la orilló a realizar tal acción. Es importante señalar que con estas obras de arte y la posterior dramatización se terminaron los miedos de Carlos, además se produjeron cambios en la relación madre-hijo, tales como independencia, expresión de amor, apertura al diálogo, comprensión, respeto y obediencia. Carlos se atrevió a expresarle a su madre un amor genuino y sin reservas a través de Los que se quieren, una caja "para que meta sus cariños, también el amor que me tiene a mí", además le confirió valor al papel que tuvo como cuidadora a lo largo de la enfermedad.

Al finalizar su proceso arteterapéutico con la obra de arte La familia, reafirmó su deseo de continuar su camino con mayor independencia, pero al mismo tiempo estaba convencido de que estaría apoyado y acompañado de su familia. Incluso dio importancia al papel de su arteterapeuta, y le reconoció el haberlo ayudado a superar sus miedos. Es así que al llegar al punto terminal de su proyecto que lo condujo a la "vida", dio un panorama general de los recursos psicológicos adquiridos y del aprendizaje de nuevas formas de afrontamiento; su maduración cognitiva y emocional, le produjo cambios significativos en su estado de ánimo, valoraciones y autopercepción, de igual forma en su manera de afrontar la vida y el mismo cáncer.

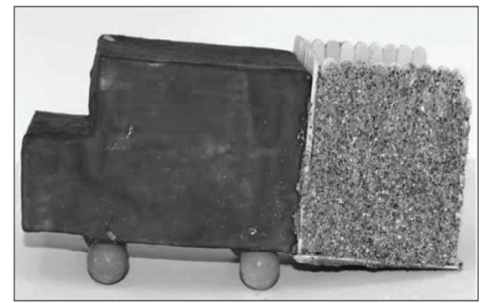

Fig. 3. Limusina

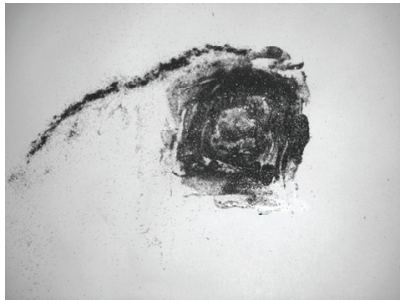

Fig. 4. Caminito

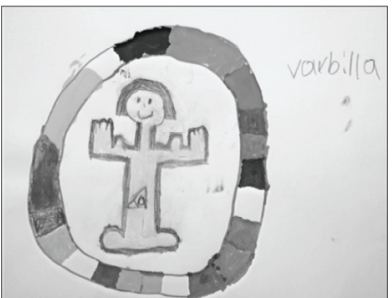

Fig. 5. Varbilla

\section{Conclusiones}

El proceso arteterapéutico llevado a cabo por Carlos, propició un proceso creativo no sólo a nivel artístico por las obras de arte realizadas, sino también porque fue posible una construcción de posibilidades para restaurar los eventos del pasado así como también el aprendizaje de nuevas formas afrontamiento. Se logró identificar la emergencia de 4 fases, propias del proceso creativo, las cuales son:

1) Preparación: la persona lleva a cabo intentos conscientes para resolver un problema, en donde usa y adapta explícitamente métodos conocidos y va procesando la información en la mente de manera abstracta (González, 2004). Corresponde a la etapa de sensibilización y psicoeducación, en la cual Carlos se empapó de toda aquella información sobre el cáncer infantil y su proceso, así mismo se le brindaron 
técnicas cognitivas para generar un autoconocimiento en lo que corresponde a sus emociones, sentimientos y pensamientos.

2) Incubación: se caracteriza por una fluidez aparente y períodos de resistencia, puede durar minutos o meses, lapso de tiempo en el que por debajo del nivel de conciencia se desencadenan procesos propios del pensamiento divergente. Estos se combinan de manera continua, contribuyendo a la gestación de la idea creativa, innovaciones provechosas o soluciones de problemas (González, 2004). Sin embargo cuando se tolera tal ambigüedad y frustración, se obtienen nuevas estructuras mentales, gracias a la flexibilidad desarrollada desde la etapa de preparación. En Carlos la incubación duró alrededor de 1 mes; propiamente ya en la etapa de Recorrido Simbólico se observó una fluidez aparente, ya que por un lado se comunicaba de manera no verbal a través sus obras artísticas, representando y depositando en ellas los conflictos emocionales que necesitaban una solución productiva. Por otra parte, se percibió un estado de resistencia al indagar vivencias en relación a la enfermedad, así como también durante el reconocimiento de sus propias emociones y sentimientos por tales sucesos. En este período su discurso estuvo plagado de frases tales como "no sé", "no me acuerdo" "no tengo idea" "feo" "bonito"; en ocasiones trataba de evitar hablar de su obra y/o experiencia pasando a otra actividad. Sin embargo el trabajo mental productivo, ocurrió de manera inaccesible a la conciencia, al explorar a través de procesos cognitivos los mejores caminos y posibilidades para solucionar sus propios problemas. En el caso de las resistencias, parecía que abandonaría su proceso arteterapéutico, sin embargo lo que estaba sucediendo era una reestructuración mental. Así mismo estaba adquiriendo una mayor fortaleza, tolerancia a la ambigüedad y a la frustración, por lo cual fue posible la culminación de la intervención.

3) Iluminación. Encuentros y desencuentros: Aquí ocurre un destello repentino, derivado de un trabajo inconsciente previo para explicarla. Según González (2004) es la etapa más placentera del proceso creativo, porque implica el chispazo o la corazonada que tiene la persona al dar con la respuesta perfecta y justa a lo que está trabajando. Es un ¡Eureka! triunfante, que ocurre después de que la mente ha realizado múltiples conexiones mentales. En Carlos sucedió cuando se le dio la oportunidad de trabajar de forma libre, en donde creó sus obras Limusina (Fig. 3) y El caminito (Fig. 4). Con estas obras convocadas se dio cuenta y con ello pudo expresar desde su propia voz que necesitaba encontrar "un camino para llegar a la vida".

4) Verificación: ocurre la resolución deliberada del problema, la persona trabaja en su idea, elaborándola de tal forma que sea comprensible para él mismo y los demás, y finalmente comunicarla. La persona realiza evaluaciones de las fases anteriores y prueba maneras para resolver un problema previamente procesado, lo revisa, corrige y vuelve a intentar hasta verificar que la idea, producto o solución es la más efectiva y adecuada (González, 2004). Carlos experimentó esta fase en un lapso de 7 meses aproximadamente, de tal modo que se trabajó teniendo como antecedente el descubrimiento realizado en la etapa de iluminación. Era evidente que su necesidad de manera metafórica era llegar a "la vida", por lo que fue preciso cons- 
truir un mapa, el cual funcionaría como marco de referencia para orientar sus pasos $\mathrm{y}$ resolver de manera literal las alteraciones emocionales asociados a la enfermedad.

Resulta conveniente mencionar que la importancia de la metodología del Arteterapia, radica en que ésta facilita el proceso creativo, a través de la actividad artística y creadora. La relación entrañable entre obra-paciente-arteterapeuta en un tiempo y un espacio definidos, promueve la búsqueda, recombinación y reorganización de posibilidades, para generar alternativas de cambio con las cuales el paciente pueda construir una realidad diferente. En esta relación, la obra de arte tiene un papel primordial debido a que en ella se deposita la psique humana, al contener aquellas experiencias que nos hablan del sufrimiento y/o bienestar emocional. Por lo que a través de la obra tanto el paciente como el arteterapeuta se comunican, estableciendo un código de comunicación que hace posible descifrar los significados del historial de las obras de arte, así como también la construcción de nuevas estructuras de pensamiento, para solucionar los conflictos psíquicos. Las fases del proceso creativo acontecidas a lo largo de la intervención, confluyeron positivamente en soluciones creativas para el desarrollo personal, las cuales vinieron de un arduo y constante trabajo, que si bien hubo resistencias afectivas y cognitivas, se logró descubrir formas para solucionar las problemáticas. Es preciso señalar, que el ¡Eureka! no ocurrió por un súbito destello mágico, sino que se originó del trabajo mental productivo que sesión tras sesión se fue elaborando. Participaron en este trabajo mental, la imaginación, la introspección, la expresión de emociones y sentimientos ante experiencias difíciles, además el niño adquirió flexibilidad y fluidez mental, desembocando en una tolerancia a la ambigüedad y frustración gracias a la reelaboración de representaciones mentales viejas y nuevas.

En resumen, el proceso creativo acontecido se caracterizó por ser dinámico y flexible, y no lineal, ya que en la búsqueda de soluciones creativas de los problemas a través de la actividad creadora, de manera inconsciente se fueron ensayando diversas posibilidades para lograr un ajuste y bienestar psicológico, a través del retorno a fases previas del proceso creativo. En este trayecto, se cambiaron las formas de percibirse a si mismo, de evaluar la enfermedad y otras situaciones difíciles, con lo que se originó un cambio en el modo de afrontarlas. Sin embargo, ante la emergencia de la ansiedad o miedo de dejar en el pasado viejas estructuras mentales y formas de actuación, porque resultaban más cómodas, el niño retornó a etapas de preparación e incubación para no claudicar, seguir reelaborando y transformándose hasta llegar a la construcción de nuevos significados y una reestructuración positiva.

\section{Aportaciones del estudio}

El Arteterapia con orientación cognitiva, para el tratamiento psicológico del proceso de la enfermedad del cáncer infantil, es un recurso valioso y benéfico que propicia cambios positivos en relación al aprendizaje de estrategias de afrontamiento favorables y el manejo de las emociones. En parte, las aportaciones de este estudio, están centradas en la atención psicológica en cada una de las fases del proceso del cáncer infantil, debido a que a lo largo de la enfermedad se presentan eventos críticos que deberían ser atendidos y solucionados en el momento en que se presentan. 
Además con este estudio se busca que el Arteterapia, sea valorado dentro del campo de la Psicooncología y la Psicología de la Salud, como un recurso psicoterapéutico ya que puede brindar herramientas psicológicas integrales y holísticas para el manejo psicosocial frente al cáncer infantil. Por lo anterior, se reconoce la importancia del arte y la actividad creadora al ofrecer diversas vías de comunicación y posibilidades para solucionar los conflictos que aquejan a las personas involucradas en el proceso del cáncer infantil. El Arteterapia con orientación cognitiva resulta ser un tipo de intervención efectiva que se vale de su procedimiento y que al conjugarse los elementos de su encuadre facilitan la comunicación y la representación de lo impronunciable o lo que es difícil de verbalizar, lo que a su vez propicia la catarsis, el abordaje de los conflictos psicosociales, su manejo y solución. A nivel teórico, el presente trabajo puede contribuir en la integración de conceptos referentes a la creatividad dentro del proceso que se genera en el Arteterapia con orientación cognitiva. Tales conceptos se refieren a las fases del proceso creativo: preparación, incubación, iluminación y verificación (González, 2004); lo anterior se propone con el objetivo facilitar la mejor comprensión del desarrollo del proceso arteterapéutico. 


\section{REFERENCIAS BIBLIOGRÁFICAS}

GONZÁLEZ ROMO, R. A. (2004). Creatividad en la investigación: persona, proceso, producto y contexto desde la experiencia del investigador. Xalapa, Universidad Veracruzana.

GONZÁLEZ ROMO, R. A.; Reyna Martínez, M. y Cano Rodríguez, C. C. (2009). "Los colores que hay en mí: una experiencia de arteterapia en pacientes oncológicos infantiles y cuidadores primarios". En Revista de Enseñanza e Investigación en Psicología, 14, 1, 77-94. México, CNEIP.

LAZARUS, R. (1999). Estrés y emoción: manejo e implicaciones en nuestra salud. España, Desclée de Brouwer.

LOTH ROZUM, A. \& Malchiodi, C. A. (2002). Cognitive-Behaviorial Approaches. En Handbook of art therapy, 72-81. E.U.A, Guilford Press.

OSORIO GUZMÁN, M. (2007). "Perspectiva de la psicología de la salud en programas holísticos de atención a pacientes pediátricos con leucemia: ilustración de una experiencia mexicana". En Avances de Psicología Latinoamericana, 25, 1, 81-110. Colombia, Universidad del Rosario.

PARSONS, M. (2002). Cómo entendemos el arte: una perspectiva cognitivoevolutiva de la experiencia estética. Barcelona, Paidós.

RODRÍGUEZ PARRA, M.J.; Esteve Zarazaga, R.M. \& López Martínez, A.E. (2002). Represión emocional y estrategias de afrontamiento en dolor crónico oncológico. Psicothema, 12(3), 339-345.

ROMERO RETES, R. (2003). La terapia psicológica adyuvante en el enfermo oncológico. En I. Caro, Psicoterapias cognitivas: evolución y comparaciones (pp. 77-94). Barcelona: Paidós.

SECRETARÍA DE SALUD. (2007). Prevención ante el avance del cáncer. Salud, 56, 4-5. Recuperado de http://www.portal.salud.gob.mx/

VIGOTSKY, L. (2006). La imaginación y el arte en la infancia. México: Ediciones Coyoacán. 